\title{
NARRATING LITERACY PRACTICES AT AN URBAN SECONDARY SCHOOL IN SURABAYA
}

\author{
FajarSusanto \\ Universitas PGRI AdiBuana Surabaya \\ fajarsusanto@unipasby.ac.id \\ Irfan Rifai \\ Universitas PGRI AdiBuana Surabaya \\ rifai_irfan@yahoo.com
}

\begin{abstract}
This study is aimed at narrating the implementation of literacy programme at an urban secondary school in Surabaya, focusing of how the school integrates and accommodates the concept of multilingualism (Java, Indonesian Language, English, French, and Japan) on its creative application and how the integration and accommodation of multilingual literacy is carried out on the day-to-day literacy practices. Drawing on qualitative data analysis gathered mainly through semi structured interviews with four teachers and two students and observations, the research findings suggest that school literacy programme is not only aimed at socializing and habituating the literacy culture within the school, but literacy programme facilitates spaces to accommodate the students' creativity in the literacy practices through their participation, involvement and engagement in designing, managing and disseminating the school programme. It can be argued, therefore, that the literacy programme at the school transcends the expectations of the school in which the initial thought and expectation are only within the boundary of socializing and habituating the literacy culture within the school, but it transforms into more advance creative spaces for the students to learn languages and gain 21 century skills.
\end{abstract}

Keywords: multilingual literacy, urban secondary school, creativity and twenty-first century skills.

\section{INTRODUCTION}

Literacy programme which is recently being a national wide programme through the implementation of a-fifteen-minute reading policy within the country has enacted attentions from the policy makers and researchers, exploring the ideas and aspects underlying the implementation of the programme and its meaning for teachers and students. As stated in Permendiknas No. 23, 2015 about PBP (Penumbuhan Budi Pekerti), literacy programme is oriented to improve and increase the reading habits among Indonesian students at all levels of education. Moreover, the implementation of the literacy programme is also often associated with the criticism about the lower rate of Indonesian literacy, as notoriously 
known as 'a tragedy of zero book'.

Recognising that the literacy programme is a crucial and strategic programme of the government, the research focuses on revealing the meanings of the programme from the actors' views is essential, informing the policy makers in regards with the implementation, the evaluation and the development of the programme. The study of literacy in fact has been widely researched in any parts of the world. The study of school literacy practices in Canada, for example, has shown that school literacy practices has been influential to construct students outof-school literacies - the skills and knowledge gained during the school literacy practices benefited students participated in the study to use and explore information and other educational activities in the internet (McTavish, 2014).In addition, the significant role of school literacy in constructing students' habits, knowledge and skills is prevalent, as the school is the perfect place to provide students with the opportunity to engage uninterrupted literacy (McTavish, 2014). Wang \& Kirkpatrick (2015) pointed out that the school is a powerful institution to nurture students with the reading and writing activities and in this sense known as literacy practices.

In addition, the study on literacy often shows that literacy programme is never neutral, it is highly embedded within the social, political and cultural boundedness which is perceived to be significant in determining the success of the programme (de Silva Joyce and Feez, 2016). The good collaboration between stake holders is significant to enhance the success of the students whether in the school or in the familial context. One of the significance benefits of social capital, the involvement of parents in educational goals, according to Papen, is an improvement of the students' achievement in the school (2016). Moreover, an experiment study conducted at two schools in the US has shown that the success of literacy programme at school can be achieved through the collaboration between school and family (Morrow \& Young, 1997).

Moreover, through the literacy programme, the school, government and parents expect to provide the students with better school environment where the students feel secure, confident, and competent to do in school.

This study is mostly concerned with the learning experiences of the teachers and students on the literacy programme and how they transform their learning experience into new more pedagogical activities. The role of teachers on the ongoing success of the literacy programme is inevitable since they have key role in guiding, supervising, managing and directing the programme. Moreover, whilst the students and the teachers are the key actors in the programme, including their voices will be generating more thorough understanding toward the success of the literacy programme. Moreover, garnering their understanding of the meaning of literacy programme can be helpful to shed alight the future school literacy practices within the country.

In a more specific, this present study focuses on the two research questions: 1). How the school literacy programme is implemented 2). How does the concept of school literacy programme is creatively constructed?

\section{METHODS AND SETTING}

This study adopts qualitative approach to get a deeper understanding of the literacy practices at an inner state Junior High School in Surabaya. Four teachers 
and two students were involved to portray the literacy programme and its meanings pertinent to the concept of multilingual literacy in their school day-today practices. Those involved teachers are form Bahasa Indonesia and English teachers who in charge of and responsible of literacy programme within the school for a couple of years whilst the students are actively involved in the school literacy programme. Their involvement in this research indicates that this research 'works with' rather than 'work for', in which this notion is crucial to capture the authenticity of their voices and as a way to reduce power relation might arise during the data collection. Their involvement also means that we value, negotiate and share experiences during the data collections particularly during interviews and observations to achieve thick data collection. We used interviews, classroom observations and supplemented by audio-taping and collection of artefacts. Teachers' participation during data collection was totally volunteer. As their participation is completely volunteer, we did not offer material benefits, but we value their stories and narrative about the literacy programme.

The primary data source of this research is derived from face-to-face individual interviews which is audio-taped and transcribed. We utilised semi structured interviews with open-ended questions. We designed and clustered our questions within three areas: 1) literacy experience, 2) current conceptions of literacy programme, 3) multilingual literacy practices. We interviewed four teachers in different places ranging from their office (literacy office teacher), library and school terrace. The diverse places for conducting interviews is also meant to set up relax and informality. This situation is important to get richer data and is trying to avoid such an 'intimidation'. The interviews took between $30 \mathrm{~min}$ to $50 \mathrm{~min}$, with the majority between $40 \mathrm{~min}$ to $45 \mathrm{~min}$. We sometimes interviewed more than twice in different times and places to clarify and get a better understanding of important issues which emerged from our observations and data transcription.

In addition to interviews, classroom observations were also conducted. This observation is aimed at enriching and supplementing the data gathered through the interviews. Two types of field notes used during observations, descriptive field notes and reflective field notes. Descriptive field notes are mostly concerned with describing activities within the classrooms, including what the students' attitudes during the literacy practices, what is the teachers doing during the literacy practices, what is the reading materials used, what is the instructions like, and what is closing activities of the literacy practices. This is important to provide a better insight of literacy practice within the classrooms. Reflective field notes, in addition, is utilised to provide some thoughts and reflections of particular interesting ideas obtained from the observations.

In addition, documents analysis is taken into consideration in data collection. The documents are used to provide contextual meanings of the teachers and students perspectives. The documents are mostly gathered from students' work book, fliers, teachers' notes, students' literacy book available in the classroom and the library and school website. However, collecting students' diary, workbook and teachers' books need to carefully pay attention particularly when the documents are about the students' affiliation school, name and a particular class. When the name or image of students is on the diary or books, blurring this potential recognition is conducted. 
The data analysis draws on interviews data with four teachers and two students who get involved in literacy programme, although the analysis itself is informed by an extensive data-set gathering from interviews with more than eight teachers and three teachers from two junior high schools within the city and intensive observations during the literacy practices. Thematic analysis is utilised to capture the themes emerged from the interviews data transcription and supplemented by field notes, and documents.

We conducted the research at a favourite school in Surabaya. This school has been and is being a top school within the city. In regard with the literacy programme, the school had implemented the literacy programme before the Government started to socialise and urge schools within the country to implement the programme. As fulfilling the ethical consent, we anonymized the name of the school.

\section{FINDINGS AND DISCUSSION}

There are three key findings will be discussed in the following three subsections. The first sub-section will be illustrating the literacy practices within the school, from the suggested literacy practices to the hybrid literacy practices. The second sub-section will be discussing the links between literacy and creativity which is emerged due to the implementation of the literacy programme. The last sub-section is highlighting literacy practices which are being medium to build on the multilingual learning environment.

\section{The different form of literacy practices}

The data findings indicate that literacy programme within the school is coconstructed by the school personnel including teachers, head school and students, suiting to the school's social and cultural condition. When the Government policy recommends that the school should implement a-fifteen-minute reading, for example, the school urges the students to read thirty minutes before the school lesson begins. One of the teachers says that

At the beginning of 2012, we started literacy programme, as the Government recommends, urges students to read a book for fifteen minutes twice or three times a week. But in 2013, end of November, we change the programme (reading), it became thirty minutes every day, except on Friday. The implementation of the programme starts from 6.30 to $7.00 \mathrm{AM}$. The idea was that, having seen that the students were eager to read by asking for another minute for reading and the school's response is positive, we started to implement a-thirty- minute reading afterwards. (Bu Yuli)

It can be recognised that the school extends the literacy practice becomes a-thirty-minute reading policy. This is due mainly to the students' expectation and the school's approval which perceive that reading and writing need more extra time. The teacher also explained that the literacy programme socialised by the government, in fact, came after the literacy programme of the school. The school had implemented a literacy programme but probably slightly different from the Government programme. The different form of literacy practices has been 
acknowledged, demonstrating that literacy, on its development is called new literacy. Literacy in this sense is seen as social practices rather than focusing only on reading and writing (Barton and Hamilton, 1998), in that literacy study focuses on the 'everyday meanings and uses of literacy in specific cultural contexts'. In other word, "literacy is always and already embedded in particular social forms of activity (Baynham \& Prinsloo, 2001: 83). The emergence of this concept is mainly due to a dissatisfaction with the concept of literacy surrounding on reading and writing (Barton, 2001). This proposition closely relates to two models of literacy which is raised by Street (1984); autonomous and ideological model. Autonomous literacy model concerns with the effects of literacy on social and cognitive practices whilst 'Ideological literacy emphasizes on literacy as social practices which are deeply embedded in social contexts (Street, 2001).

In regard with the literacy practices - reading and writing before the lesson starts -, the literacy programme is also concerned with the book that the students need to bring and read in the classroom and other practical matters in line with literacy practices within the classroom.

It used to be that students should bring their own books (to read in classroom). But after knowing it became their habits, we asked them to put their books on the self in front of the classroom. It is like book corner...at the beginning of the new academic year, they need to bring their own books, place it at the book corner, read and make a note on the work book. They need to tidy it up. They need to manage their own books, their work book and book corner. To encourage their book management, we have competitions. (Bu Yuli)

The key important point derived from the extract above is that when the expected goals have already been achieved, the teachers need to creatively think the follow up activities and programme. In this sense, the school has modified the creative ways of the programme by providing space to the students in regard with what they should do or what they need to do with their literacy practices, including encouragement and motivation to immerse the students with the programme. The creative thoughts of the teachers in providing spaces for the students is closely related to their belief that school literacy practices deeply benefits the students' skills. The finding is in line with the previous study that show that the teachers' belief about teaching literacy is informed by their previous experience (Sandvik, van Daal, Ader, 2014) and in this sense, the teachers in this study is informed by the previous experience of conducting school literacy practices.

Instead of facilitating students with motivations, the teachers also provide some technical guidance in connection with literacy practices within the school. The guidance can come into various forms, as illustrated in the following.

For this time, we are still concerned with raising (students) awareness through, just I said previously, after reading, (they should) write, and make a resume. The format has been provided, then bound and collected to Bahasa Indonesia teacher or class teacher to get a signature. (The signature) as a proof that they have done literacy activities. That is what we say every time, yes, so after having read, the students are expected to 
be able to write the resume, the physical evidences are collected. When there is a certain even, for example, commemorate of Independence Day of 17 August, we include(their work) in one of the contests that are set by OSIS. (Bu Wiwik).

The demands of making such as a resume after reading a book is designed by the school to be a purposeful evident for the school and for the students that they practice literacy - reading and writing. Instead of being an artefact, these literacy practices are meaningful to encourage and prepare students to participate in particular competitions. This finding accords the US's literacy programme which according to National Center for Education Statistics (cited by Campbell, Kelly, Mullins, Martin, \& Sainsbury, 2001), is aimed at developing "the ability to understand and use those written language forms required by society and/or valued by the individuals... They read to learn, to participate in communities of readers in school and everyday life, and for enjoyment". In addition, this finding is in line with the concept that literacy is situatedness (Street, 1984), in that literacy is heavily influenced by the socio-cultural and ideological. When the literacy is heavily affected by the socio-cultural and ideological factors, the different form of the literacy practices with other schools is apparent. When the school's orientation is the outputs of literacy practices and accommodation of the local values of Indonesian tradition - oral literacy - the school places a greater attention to prepare programmes aiming at facilitating and achieving the outputs of the programme including a-Friday-speech competition and other targeted competitions.

\section{Literacy is an arena for generating creativity}

From the data sets it is found that literacy programme which is initially oriented and targeted for improving the students' reading habits, on its development, it becomes the medium for generating creativity.

\section{Extract}

There are so many advantages of literacy. Literacy brings many changes of the students because of the types of reading they are read. The students know many things, from being unable to know till being able to know, from being unable to make something till being able to make something; film, even such as journalism, standup comedy... There are three students for example, follow journalistic contest, whilst others take part in the short movie contest. Their skills (journalism \& choreographer) are inspired by reading books, by literacy. (Bu Widi)

The key important point in this finding is that, literacy programme which emphasising on reading and writing can be a powerful programme and being source of inspirations of the students to be more creative. In this sense, students' creativity shown through their intuitive and productive work is perceived by the teachers to be the result of the reading habits. The term creativity in this context is often associated with the newness/very current activities among the students within the school. This finding is consistent with the study conducted by David 
Oslon (1977) who describes that literacy is an instrument of cultural and scientific development and cognitive development.

Moreover, the research finding demonstrates that students, in fact, are autonomous learners, suggesting that they are possessing skills and competence in literacy practices. In other word, the students can be independent to select appropriate and creative literacy practices, in which in many cases without the direct instructions and guidance from the teachers. This finding accords with the concept of 'agent' in literacy practices that the students are not the passive recipients and executors (Papen, 2016: 11) of the policy implementation from the government, they play active role on initiating, developing and creating the ways to carry out literacy practices. This current research finding also supports the previous study which shows that social interaction when using technology deeply facilitates the acquisition of digital literacy practices (Davidson, 2011).

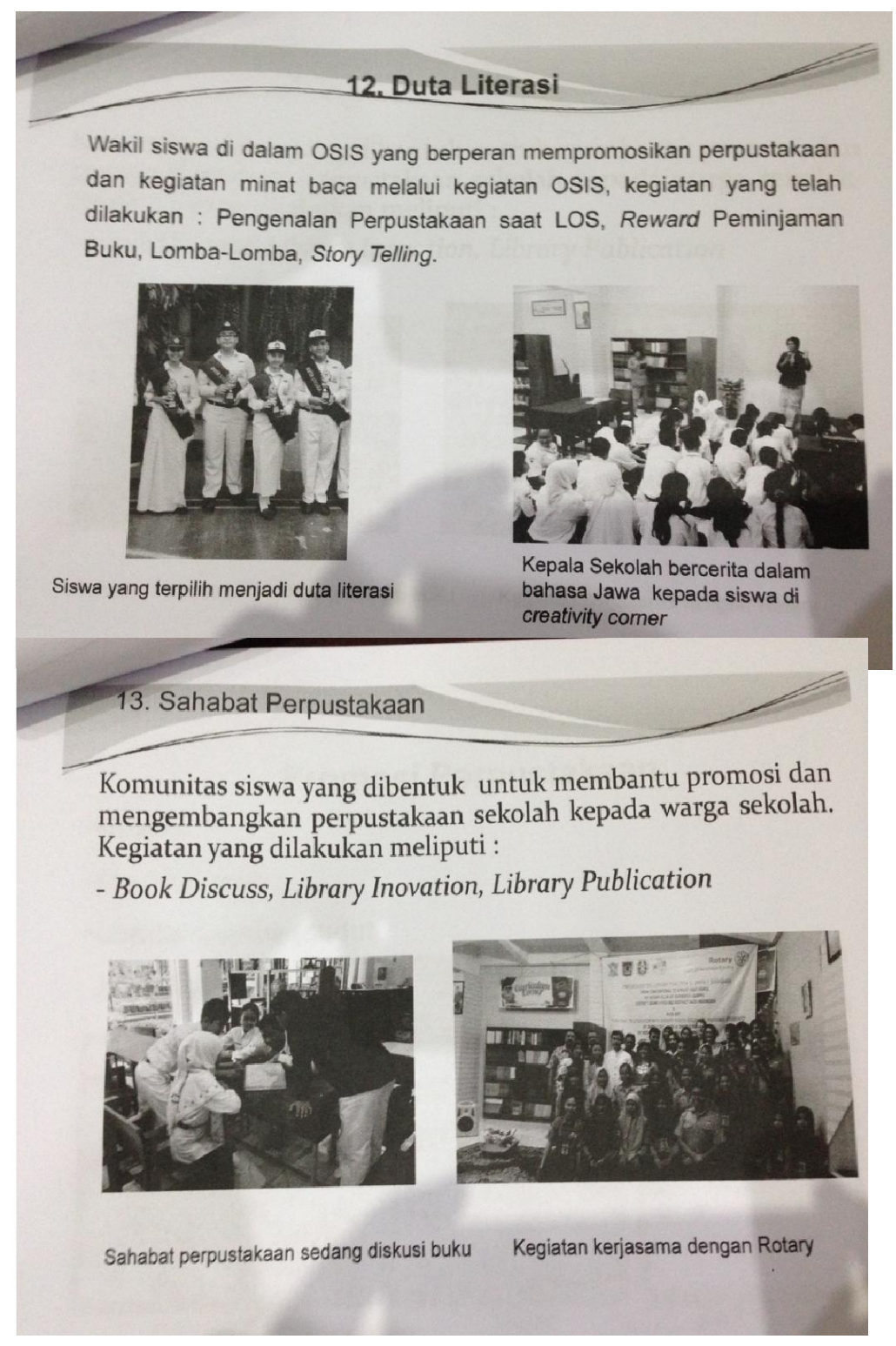


The teacher's story in the extract above indicates that the teachers have never imagined previously of the students' activities and achievement, being able to create short movies and participated in journalistic competitions. The extract has been an evident to show teachers' acknowledgment that the students' skills and achievement are inspired by literacy practices. This current finding corroborates the concept of learners' autonomy which states that students is an agent and social actor who have their competence and often position themselves as initiators of activities rather than passive consumers (Yelland, 2010). The role of teachers in this programme is to facilitate and promote the students' awareness and direct their learning to maximise their achievements.

Moreover, through literacy practices, it helps reveals the students' hidden skills. For example, the students utilise literacy practices to develop their knowledge in information technology through the setting up of an online application to spread out the literacy programme to wider participants. They use not only the traditional way of disseminating the literacy programme such as through fliers, newspapers, and school leaflet, but they can now design the programme which can connect the book sources in the library and the books in other places such as in the school lobby, hall, and in the classrooms in just a-click, as is illustrated by one of the students in the following

\section{Extract}

Literacy and technology. So, like this Sir, in this library I am as IT team. Here, IT team, in fact, only has job to manage the library's social media and website...actually we here not only made a website just only for sharing us in the library, but also we ought to be what we call...the library must be useful, is it right Sir? So I and students, our team support, added e-book, e-journal sir. Thus, the e-books, novels, there are also encyclopedia till popular novels from Indonesian language until English language, and also there are lesson books of foreign languages. After that e-study for lesson books for grade 7, 8, 9 and then guidance books of our teachers downloaded from Kemendikbud website and the third e-journals are the electronic journals that we collected for teachers. (Aisyah)

It is well explained therefore that the implications of literacy practices are multidimensional, ranging from generating creativity to unrevealing the students' hidden skills. The students narrated that they gain such skills is perceived to be a result of reading activities, since the literacy practices has been implemented within the school.

However, literacy practices are not always a linear process to be a medium of developing students' knowledge and skills. One of the students, Rima, for example, has narrated that when she was in the first year of her study, she is not really interested in literacy programme and tended to have negative views of the habit of reading and writing implemented by the school. However, when she was in the half of her second semester, she became more interested in the school programme. Her enthusiasm based on her story is primarily about the force from the teachers which did not allow her to read the books other than the books available in the classrooms and the support of the positive school environment (Field note). Habituation and a prolonged enforcement, in this sense, is seemingly 
a significant instrument to raise students' awareness in the reading and writing activities.

In addition, literacy programme has been an arena for promoting foreign languages and preserving regional languages. On one hand, literacy programme can be a means of supporting the government policy on sustaining and preserving regional languages through the use of local language (Java) in a speech contest and at a regular or daily practice, and on the other hand, it can be a medium to socialise and promote foreign languages such as Korean, Japanese and other foreign language. The following section discusses literacy and multilingual practices.

\section{Literacy programme as an arena for multilingual learning environment}

Another interesting research finding is that literacy which is implemented by the school is perceived by the teachers beyond the recommended Government programme and the school's expectations, in that initially it is only focused on surrounding reading and writing activities before the lesson begins, but it is now being an arena to acquire foreign languages and promote a local language. One of the teachers said that to accommodate the students' enthusiasm in learning languages and as the way to preserve local language, the school started to sets up oral literacy as an integral part of the school programme.

The reason behind providing the space for oral literacy is that it is a prevalent tradition among Indonesian for many years. The programme, therefore, is not only reading and writing activities, it is also about the speaking activity, adopting to the local value of oral literacy. Interestingly, this oral literacy is not limited to the use of local language (Javanese language), but it ranges from Bahasa Indonesia, English, Japanese, French, and Arabic.

It not only reads and writes but also after that tells a tale. So, what has been read, written then conveyed. Telling a tale is not only in bahasa Indonesia, there is Javanese, there is Korean, there is English, and sometimes in order not monotone, we made variation, the head master tell a tale, and also teachers. Even the students' parents also present primarily for Javanese that although Javanese is very well-known in Javanese island, it is still difficult for students especially for Kromo Inggil to acquire. (Bu Wiwik)

This finding corroborates the concept of multilingual literacy referring to "the multiplicity and complexity of individuals and group repertoires" (Jones and Jones, 2000). The concept of multilingual literacy in the school literacy programme, however, is about the required twenty-first century skills that the students need to acquire. In addition to the idea of socialising twenty-first century skills which are often associated with acquiring global languages orally, multilingual literacy is also about socialising and acquiring those languages in the written forms. Moreover, multilingual literacy is also about strengthening students' identity through the practice use of different levels of Javanese language. What an interesting point to note is that the creative implementation of this programme in that, whilst the school promotes the acquisition of particular foreign language (English, French, Japanese, Korean) which is crucial for the global interactions 
and competitiveness (de Silva Joyce and Feez, 2016), the school also encourages students to maintain local languages of the students.

\section{CONCLUSION}

It can be concluded that the policy of literacy programme implemented by the Government and school is deeply influenced by social, cultural and ideological factors. The policy, however, is not always top-down; rather, it is often bottom-up where the ideas and creativity of literacy practices are generated from the collaboration between the school community including teachers, students, staffs and parents and not from the Government alone. This study, therefore, reiterates the previous research about social capital in education which demonstrates that the integration of school community to achieve better students' outcome and skills are clear (Coleman, 1988).

Moreover, this study becomes an evident to show that school literacy in different forms can be a meaningful medium for creativity and acquiring twentyfirst century skills. The research findings have consistently indicated that through the immersion of the teachers and students in literacy practices, the creative forms of literacy practices can be enacted. These forms of literacy practices are perceived by the teachers and students benefitted them to acquire the current skills, twenty-first century skills. The findings also indicate that the concept of literacy is flexible and fluid, as there have been a dialoguing and negotiating between school personnel and the students which eventually shape to construct multilingual literacy within the school.

In addition, the implementation of the literacy programme does not always align with the Government policy. It sometimes transcends the policy, providing some alternative and creative ways in its implementation. However, as the data mostly generated from the interviews with the actors who get involved in literacy programme, the data presented cannot be anticipated from being the representation of a specific group. A further research, therefore, should also include more participants so that the results would be more diverse to capture the actors' view point.

\section{ACKNOWLEDGMENT}

Our deepest gratitude goes to the Ministry of Research, Technology and Higher Education (KEMENRISTEKDIKTI) for its funding support via the schema 'Penelitian Dosen Pemula'. We are also grateful to the head masters, teachers, students, and at "Prima" Junior High Schools (anonymized) and colleagues in English Language Education Department Universitas PGRI Adi Buana Surabaya, all of whom have provided support and help during this research.

\section{REFERENCE}

Baynham, Mike and Prinsloo, Mastin. 2009. The Future of Literacy Studies. The United Kingdom. Palgrave MacMillan.

Campbell, J. R., Kelly, D. L., Mullis, I. V. S., Martin, M. O., \& Sainsbury,M. (2001).Fmmework and spec\$cationsfor PIRLS assessment 2001. Chestnut Hill, MA: Boston College. 
Coleman, J. S. (1988). Social capital in the creation of human capital. American journal of sociology, 94, S95-S120.

David Barton, Marilyn Martin-Jones, Kathryn Jones-Multilingual Literacies_ Reading and Writing Different Worlds (2002)

Davidson, C. (2011). Seeking the green basilisk lizard; acquiring digital literacy practices in the home. Journal of Early Childhood Literacy 12 (1) 24-45.

De Silva Joyce, Helen and Feez, Susan. 2016. Exploring Literacies: Theory, Research and Practice. The United Kingdom: Palgrave Macmillan.

Martin-Jones, Marilyn\& Jones, Kathryn. 2000. Multilingual literacies: Reading and Writing Different Worlds. Netherland: John Benjamins.

McTravis, M. (2014). "I'll do it my own way!": a young child's appropriation and recontextualisation pf school literacy practices in out-of-school spaces. Journal of Childhood Literacy 14(3) 319-344.

Molle, D. Sato, E. Boals, T. and Hedgspeth, C. A. 2015. Multilingual Learners and Academic Literacies_S Sociocultural Contexts of Literacy Development in Adolescents. New York: Routledge.

Morrow, L. M. \& Young, J. (1997). A collaborative Family Literacy Program: The Effects on Children's Motivation and Literacy Achievement. Early Child Development and Care (127-128) pp. 13-25

National Center for Education Statistics (NCES). (2000). Teacher use of computerand the Internet in public school, U..S. Department of Education, Office of Educational Research and Improvement, NCES 2000-090. Retrieved September 16, 2007, from http:1/nces.ed.govlpubsearch/pubsinfo. asp!pubid $=2000090$

Pahl, Kate and Roswell, Jenifer. 2005. Literacy and Education: Understanding the New LiteracyStudies in the Classroom.Great Britain. Paul Chapman Publishing.

Pahl, Kate and Roswell, Jenifer. 2015. The Routledge Handbook of Literacy Studies. London and New York. Routledge.

Papen, Uta. 2016. Literacy and Education: Policy, practice and public opinion. New York: Rouledge.

Permendiknas, No. 23, 2015 about PBP (Penumbuhan Budi Pekerti).

Sandvik, J. M., van Daal, V. HP., Ader, H. J. (2014). Emergent literacy: preschool teachers' beliefs and practices. Journal of Early Childhood Literacy. 14 (1) 28-52.

Yelland N (2010) New technologies, playful experiences, and multimodal learning. In: Berson I and Berson M (eds) High-tech tots: Childhood in a digital world. Charlotte, NC: Information Age Publishing, pp. 5-22. 